\title{
Characteristics and surgical outcomes of pediatric rhegmatogenous retinal detachment
}

This article was published in the following Dove Press journal:

Clinical Ophthalmology

19 June 2012

Number of times this article has been viewed

\section{Yoshihiko Oono \\ Koji Uehara \\ Masatoshi Haruta \\ Ryoji Yamakawa}

Department of Ophthalmology, Kurume University School of Medicine, Kurume, Japan
Correspondence: Yoshihiko Oono Department of Ophthalmology, Kurume University School of Medicine, 67 Asahi-machi, Kurume, Fukuoka 830-00II, Japan $\mathrm{Tel}+8$ I 9423 I 7574 Fax +81942370324

Email ohno_yoshihiko@kurume-u.ac.jp
Purpose: To describe the characteristics and surgical outcomes of pediatric rhegmatogenous retinal detachment.

Methods: A retrospective study of pediatric patients (15 years old or younger) who had undergone primary surgery for rhegmatogenous retinal detachment was conducted. Patients were divided into five groups according to the predisposing factors: trauma (group 1), myopia (group 2), atopic dermatitis (group 3), congenital or developmental anomalies (group 4), and others (group 5).

Results: A total of 48 eyes of 44 patients were included in this study. There were 18 eyes $(37.5 \%)$ in group 1 , twelve eyes $(25.0 \%)$ in group 2 , six eyes $(12.5 \%)$ in group 3 , five eyes $(10.4 \%)$ in group 4 , and seven eyes $(14.6 \%)$ in group 5 . The initial retinal reattachment rate was $89 \%$ in group $1,100 \%$ in group $2,83 \%$ in group $3,20 \%$ in group 4 , and $86 \%$ in group 5 $(P=0.002)$. The final retinal reattachment rate was $100 \%$ in group $1,100 \%$ in group $2,100 \%$ in group $3,80 \%$ in group 4 , and $86 \%$ in group $5(P=0.16)$. The frequency of visual acuity of 0.1 or better after surgery was $100 \%$ in group $1,92 \%$ in group $2,83 \%$ in group $3,40 \%$ in group 4 , and $71 \%$ in group $5(P=0.01)$.

Conclusion: The overall surgical outcome was successful, but the patients in group 4 had the lowest initial reattachment rate and the worst visual prognosis.

Keywords: children, detached retina, surgical outcome, predisposing factor

\section{Introduction}

Rhegmatogenous retinal detachment (RRD) in a pediatric population is rare compared with adults and the clinical features are quite different. It often presents with a longer duration of detachment, proliferative vitreoretinopathy (PVR), and a macula involving retinal detachment. It also has some predisposing factors, such as trauma, developmental abnormalities, myopia, preceding uveitis, atopic dermatitis, and previous intraocular surgery. ${ }^{1-5}$ However, the clinical features vary by report. Here, we describe the characteristics and surgical outcomes of pediatric RRD patients in our hospital.

\section{Patients and methods}

We conducted a retrospective study of pediatric patients (15 years old or younger) who underwent primary surgery for RRD at Kurume University Hospital, Kurume, Fukuoka, Japan, between November 1997 and August 2008. Patients with perforating ocular trauma were excluded from the study. Patients were divided into five groups according to the predisposing factors. Patients with a trauma history were included in group 1. Patients with myopia more than -3 diopters (D) but without a history of 
trauma, atopic dermatitis, or congenital or developmental ocular anomalies were included in group 2. Patients with atopic dermatitis were included in group 3. Patients with congenital or developmental ocular anomalies were included in group 4. Other patients without obvious predisposing factors were included in group 5. Previous intraocular surgery and preceding uveitis were not present in any of the patients in this study.

The ophthalmic findings recorded at presentation included visual acuity, refractive status, macula status, type of breaks, extent of subretinal fluid, and presence of PVR of grade $\mathrm{C}$ or worse. ${ }^{6}$ Initial reattachment was defined as complete retinal reattachment following the initial surgery with or without the use of silicone oil, and final reattachment was defined as complete retinal attachment in the absence of silicone oil. Patients with no significant problems after surgery were monitored by local ophthalmologists.

The visual acuities of counting fingers, hand movements, light perception, and no-light perception were assigned ratios of $0.005,0.002,0.001$, and 0.0005 , respectively, for statistical calculations. Visual acuity was measured with a Landolt $\mathrm{C}$ chart and converted to a logarithmic scale of the minimum angle of resolution ( $\log$ MAR) to perform calculations.

A conventional external approach with scleral buckling was performed as far as possible in patients with visible retinal breaks. Three-port vitrectomy was performed in patients with obscure ocular media, undetected breaks, extensive retinal tears, complicated retinal detachment, and the presence of significant PVR.

Univariate analyses using the Mann-Whitney U test were used for unpaired data. The chi-square test or Fisher's exact test was used for categorical data. Statistical significance was defined as $P<0.05$.

\section{Results}

Surgery for RRD was performed in 48 eyes of 44 patients ( 39 eyes of 35 boys and nine eyes of nine girls). The average age was 12.3 years (range, $4-15$ years). The mean follow-up period was 24 months (range, 3-98 months). The initial retinal reattachment rate was $83 \%$ (40 eyes) and the final reattachment rate was 96\% (46 eyes). Scleral buckling was performed as initial surgery in 37 eyes (77\%) and vitrectomy was performed in eleven eyes $(23 \%)$. As for the scleral buckling, two eyes had encircling plus segmental buckling and the others had segmental scleral buckling alone. Silicone oil was used in nine eyes and perfluropropane gas was used in two eyes. The causes of primary failure included PVR (six eyes), a new break (one eye), and an inadequate buckle (one eye).

The characteristics of the five groups are presented in Table 1. A predominance of males was observed in all groups, especially in group 2 . The patients in group 4 developed the detachment at a significantly younger age than patients in the other groups. A retinal break was found during vitrectomy in three patients who did not have retinal breaks detected preoperatively. The frequency of total retinal detachment, detached macula, and PVR grade C or worse was more common in group 4 than in the other groups, but there was no significant difference. The trauma in group 1 was caused by a ball while playing sports (eleven eyes), a blow (two eyes), a ballpoint pen (one eye), a pebble (one eye), and another person's head (one eye), while the cause was unknown in two eyes. One eye in group 3 that had longstanding retinal detachment with PVR had coexisting total lens opacity. The abnormalities in group 4 were familial exudative vitreoretinopathy (FEVR) (three eyes), morning glory syndrome (MGS) (one eye), and Coats' disease (one eye). The three patients with FEVR

Table I Demographic characteristics in the five study groups

\begin{tabular}{|c|c|c|c|c|c|c|}
\hline & Group I $(n=18)$ & Group $2(n=12)$ & Group $3(n=6)$ & Group $4(n=5)$ & Group $5(n=7)$ & $P$ \\
\hline Male* & $16(89)$ & II (92) & $4(67)$ & $3(60)$ & $5(7 I)$ & 0.37 \\
\hline Age $(y r s)($ mean $\pm S D)$ & $12.3 \pm 2.1$ & $14.2 \pm 1.0$ & $12.5 \pm 1.9$ & $7.8 \pm 4.7$ & $11.9 \pm 3.1$ & \\
\hline \multicolumn{7}{|l|}{ Type of breaks } \\
\hline Round hole with lattice* & I (6) & $10(83)$ & $2(33)$ & 0 & $3(43)$ & \\
\hline Round hole without lattice* & $13(72)$ & 0 & 0 & $3(60)$ & 0 & \\
\hline Tear* & 0 & I (8) & 0 & 0 & $3(43)$ & \\
\hline Giant tear* & 0 & I (8) & 0 & 0 & I (14) & \\
\hline Oral dialysis* & $4(22)$ & 0 & $3(50)$ & 0 & 0 & \\
\hline Undetected* & 0 & 0 & I (17) & $2(40)$ & 0 & \\
\hline Total retinal detachment* & I (6) & $2(17)$ & I (17) & $2(40)$ & I (14) & 0.43 \\
\hline Macula off* & $4(22)$ & $3(25)$ & $3(50)$ & $3(60)$ & $3(43)$ & 0.4 \\
\hline PVR grade C or worse* & $2(11)$ & I (8) & I (I7) & $2(40)$ & I (14) & 0.53 \\
\hline
\end{tabular}

Note: *Number (\%) of eyes.

Abbreviations: PVR, proliferative vitreoretinopathy; SD, standard deviation. 
had no exudation. One patient with FEVR had a small retinal break close to a falciform retinal fold, which progressed to total retinal detachment during follow-up. Another had a retinal hole in the temporal peripheral avascular zone, which caused shallow retinal detachment not involving fovea, and the third had an old retinal detachment with extensive subretinal strand and macular hole, which resulted from a retinal hole in the temporal peripheral avascular zone. The patient with MGS developed total detachment caused by a slit-like break at the margin of the excavated disc with fibrous tissue. The patient with Coats' disease developed peripheral exudative retinal detachment with hard exudate in the macula and a retinal hole occurred in the detachment during follow-up.

The refractive statuses of the five groups are presented in Table 2. Preoperative refractive status could not be measured in three eyes. The frequency of myopia more than $-3 \mathrm{D}$ was $28 \%$ (five eyes) in group 1, 100\% (twelve eyes) in group 2, $40 \%$ (two eyes) in group 3, and 25\% (one eye) in group 4 . The frequency of myopia over the entire study was $44 \%$.

The surgical procedures and outcomes in the five groups are presented in Table 3. The overall surgical outcome was successful, however, in group 4, the frequency of visual acuity of 0.1 or better after surgery, the initial retinal reattachment rate, and the mean number of surgeries were significantly worse than in other groups.

\section{Discussion}

Trauma has been reported as one of the most common predisposing factors in pediatric RRD. The frequency of trauma has been reported to range from $21.9 \%$ to $43 \%{ }^{1-5}$ and most authors report a higher incidence in males than females. In our study, more than one-third of the cases $(38 \%)$ were in the trauma group and the frequency of males was $89 \%$. The predominance of males among traumatic patients may be related to higher exposure to trauma such as being hit by a ball during playing sports. ${ }^{2}$ However, a higher incidence in males was also observed in other groups, especially in group 2.

Myopia is an important factor in Asians ${ }^{2,3}$ and its frequency ranges from $17 \%$ to $38 \% .^{1-5}$ Though there were differences in the prevalence of refractive errors between ethnic groups, Asians had the highest prevalence for myopia. ${ }^{7}$ In our study, the frequency of myopia in group 2 was $25 \%$ and the frequency of myopia over the entire study was $44 \%$. However, the definition of myopia in previous reports ranged from $-3 \mathrm{D}$ to $-6 \mathrm{D} .{ }^{1-5}$ It was reported that the risk for idiopathic RRD increased tenfold compared with a nonmyopic eye, if the refractive error was greater than -3 D. ${ }^{8}$ However, it is difficult to clearly define myopia because clinical findings for emmetropic and moderate myopic eyes are not very different. The patients of group 2 were thought to have adult retinal detachment with early onset.

RRD associated with atopic dermatitis, one of the most common forms of dermatitis in Japan, has been increasing recently, and the prevalence of atopic dermatitis in Japanese elementary schoolchildren has been reported to be about $10 \% .^{9}$ Although there have been several theories about the pathogenesis of retinal detachment associated with atopic dermatitis, the mechanism of break formation is unclear at present. As for the types of break, in our study three of six breaks were caused by oral dialysis. Takahashi et al reported that retinal dialysis may result directly by slapping the eye, since the force would strongly affect that area of the eye under blunt trauma. ${ }^{10}$ The frequency of myopia more than $-3 \mathrm{D}$ of group 3 was relatively high at $40 \%$. In group 3 , blunt trauma and myopia might also contribute to the pathogenesis of RRD.

In Asian countries such as Japan and Taiwan, there is a high incidence of FEVR, accounting for $13 \%$ to $20 \%$ of pediatric RRD. ${ }^{3-5}$ However, in our study, the rate of FEVR in subjects was low at $6.3 \%$. Some FEVR patients could have been included in group 5 without being diagnosed as FEVR, as there was only minute peripheral vascular abnormality. More careful attention is needed for the diagnosis of FEVR in pediatric RRD, as its protean manifestations are easily mistaken for other ocular disorders. ${ }^{4,5,11}$ The patients in group 4 developed RRD at a younger age than the other groups and undetected breaks, total retinal detachment, macula off, and PVR were more common.

Table 2 Refractive statuses in the five study groups

\begin{tabular}{|c|c|c|c|c|c|}
\hline Refractive status & Group I $(n=18)$ & Group $2(n=12)$ & Group $3(n=5)$ & Group $4(n=4)$ & Group $5(n=6)$ \\
\hline Spherical equivalent (mean $\pm S D$ ) (D) & $-2.1 \pm 3.3$ & $-6.3 \pm 1.8$ & $-3.8 \pm 2.7$ & $2.0 \pm 11.7$ & $-1.0 \pm 1.0$ \\
\hline Miopia more than $-3 \mathrm{D}^{*}$ & $5(28)$ & $12(100)$ & $2(40)$ & I (25) & 0 \\
\hline Moderate myopia* & $4(22)$ & $10(83)$ & I (20) & 0 & 0 \\
\hline High myopia* & I (6) & $2(17)$ & I (20) & I (25) & 0 \\
\hline
\end{tabular}

Notes: *Number (\%) of eyes. Moderate myopia $=$ from -3 D to less than $-8 \mathrm{D}$; high myopia $=-8 \mathrm{D}$ or higher.

Abbreviations: D, diopters; SD, standard deviation. 
Table 3 Surgical procedures and outcomes in the five study groups

\begin{tabular}{|c|c|c|c|c|c|c|}
\hline & Group I $(n=18)$ & Group $2(n=12)$ & Group $3(n=6)$ & Group $4(n=5)$ & Group $5(n=7)$ & $P$ \\
\hline \multicolumn{7}{|l|}{ Preoperative visual acuity } \\
\hline In logMAR (mean $\pm S D)$ & $0.22 \pm 0.55$ & $0.34 \pm 0.84$ & $0.88 \pm 1.06$ & $1.51 \pm 1.51$ & $0.61 \pm 1.09$ & \\
\hline$\geq 0 . I^{*}$ & $16(89)$ & $9(75)$ & $3(50)$ & $2(40)$ & $5(7 I)$ & 0.15 \\
\hline \multicolumn{7}{|l|}{ Final visual acuity } \\
\hline In logMAR (mean $\pm S D)$ & $0.04 \pm 0.42$ & $0.24 \pm 0.67$ & $0.36 \pm 0.84$ & $1.23 \pm 1.36$ & $0.54 \pm 1.34$ & \\
\hline$\geq 0.1^{*}$ & $18(100)$ & $11(92)$ & $5(83)$ & $2(40)$ & $5(7 I)$ & 0.01 \\
\hline Initial retinal reattachment* & $16(89)$ & $12(100)$ & $5(83)$ & I (20) & $6(86)$ & 0.002 \\
\hline Final retinal reattachment* & $18(100)$ & $12(100)$ & $6(100)$ & $4(80)$ & $6(86)$ & 0.16 \\
\hline \multicolumn{7}{|l|}{ Initial procedure } \\
\hline Scleral buckling* & $13(72)$ & $11(92)$ & $5(83)$ & $2(40)$ & $6(86)$ & 0.2 \\
\hline Vitrectomy* & $5(28)$ & I (8) & $I(17)$ & $3(60)$ & I (14) & \\
\hline $\begin{array}{l}\text { Number of surgical } \\
\text { procedures (mean } \pm S D \text { ) }\end{array}$ & $1.4 \pm 1.0$ & $\mathrm{I} . \mathrm{I} \pm 0.3$ & $1.3 \pm 0.8$ & $2.8 \pm 1.5$ & $1.4 \pm 1.1$ & \\
\hline
\end{tabular}

Note: *Number (\%) of eyes.

Abbreviations: logMAR, logarithmic scale of the minimum angle of resolution; SD, standard deviation.

Therefore, the patients in this category will often require vitrectomy as an initial surgical procedure.

In cases in which a retinal break was precisely localized, scleral buckling allowed reattachment of the retina at a high rate similar to that expected in adults with retinal detachment. However, the initial reattachment rate after vitrectomy was not satisfactory. It is often difficult to perform a complete removal of the cortical vitreous on the detached retina, as there is less frequent posterior vitreous detachment and stronger vitreoretinal adhesion in pediatric RRD patients. Particularly in patients with FEVR, dissection of the vitreous in the peripheral avascular area is very difficult, since the vitreoretinal adhesions are so strong that iatrogenic retinal breaks easily occur. ${ }^{12}$ Furthermore, since fibrovascular proliferation extended to the pars plicata in the patient with a falciform retinal fold, the placement of the infusion cannula and the removal of the fibrovascular proliferation were difficult. Therefore, we placed the infusion cannula in the inferonasal segment and removed the cortical vitreous and the fibrovascular proliferation as much as possible with triamcinolone-acetonide-assisted 25 -gauge vitrectomy to facilitate easy access to the small space in pediatric eyes. ${ }^{13,14}$ However, the iatrogenic retinal break reopened under the silicone oil and retinal redetachment occurred. The etiology of MGS is unknown, and the treatment for retinal detachment associated with this syndrome is controversial. We considered traction as the pathogenesis of retinal detachment and performed vitrectomy to release traction. However, this case required multiple surgeries because of the difficulty in completely removing the cortical vitreous and the multiple iatrogenic retinal breaks. In addition, postoperative problems peculiar to pediatric patients include higher intraocular cellular activity and difficulty in maintaining a posture. Therefore, the possibility of redetachment and PVR after surgery is higher in patients requiring vitrectomy than in the patients requiring buckling surgery. We hope that newer materials and instruments will improve surgical outcomes in the future.

We have described the characteristics and surgical outcomes of pediatric RRD patients in our hospital. However, our study is limited by its retrospective nature and the small number of patients, especially in group 4. Moreover, our study included some patients with short follow-up. It is difficult to evaluate the surgical outcomes for pediatric RRD patients from the results of our study alone. Also, it seems that the poor surgical outcomes in patients with congenital or developmental ocular anomalies were primarily caused by delayed diagnosis and prolonged retinal detachment. Thus, early detection and early treatment are the most important ways to improve the surgical outcomes of pediatric RRD.

\section{Disclosure}

The authors indicate no financial conflicts of interest in this work.

\section{References}

1. Gonzales CR, Singh S, Yu F, Kreiger AE, Gupta A, Schwartz SD. Pediatric rhegmatogenous retinal detachment: clinical features and surgical outcomes. Retina. 2008;28(6):847-852.

2. Wang NK, Tsai CH, Chen YP, et al. Pediatric rhegmatogenous retinal detachment in East Asians. Ophthalmology. 2005;112(11): 1890-1895.

3. Chen SN, Jiunn-Feng H, Te-Cheng Y. Pediatric rhegmatogenous retinal detachment in Taiwan. Retina. 2006;26(4):410-414.

4. Yokoyama T, Kato T, Minamoto A, et al. Characteristics and surgical outcomes of paediatric retinal detachment. Eye. 2004;18(9):889-892.

5. Akabane N, Yamamoto S, Tsukahara I, et al. Surgical outcomes in juvenile retinal detachment. Jpn J Ophthalmol. 2001;45(4):409-411. 
6. Machemer R, Aaberg TM, Freeman HM, Irvine AR, Lean JS, Michels RM. An updated classification of retinal detachment with proliferative vitreoretinopathy. Am J Ophthalmol. 1991;112(2):159-165.

7. Kleinstein RN, Jones LA, Hullett S, et al. Refractive error and ethnicity in children. Arch Ophthalmol. 2003;121(8):1141-1147.

8. Risk factors for idiopathic rhegmatogenous retinal detachment. The Eye Disease Case-Control Study Groups. Am J Epidemiol. 1993;137(7):749-757.

9. Saeki H, Iizuka H, Akasaka T, et al. Prevalence of atopic dermatitis in Japanese elementary schoolchildren. Br J Dermatol. 2005;152(1): 110-114.

10. Takahashi M, Suzuma K, Inaba I, Ogura Y, Yoneda K, Okamoto H. Retinal detachment associated with atopic dermatitis. Br JOphthalmol. 1996;80(1): 54-57.
11. Ranchod TM, Ho LY, Drenser KY, et al. Clinical presentation of familial exudative vitreoretionpathy. Ophthalmology. 2011;118(10): 2070-2075.

12. Ikeda T, Fujikado T, Tano Y, et al. Vitrecomy for rhegmatogenous or tractional retinal detachment with familial exudative vitreoretionpathy. Ophthalmology. 1999;106(6):1081-1085.

13. Peyman GA, Cheema R, Conway MD, Fang T. Triamcinolone acetonide as an aid to visualization of the vitreous and the posterior hyaloid during pars plana vitrectomy. Retina. 2000;20(5):554-555.

14. Gonzales CR, Singh S, Schwartz SD. 25-Gauge vitrectomy for paediatric vitreoretinal conditions. Br J Ophthalmol. 2009;93(6):787-790.
Clinical Ophthalmology

\section{Publish your work in this journal}

Clinical Ophthalmology is an international, peer-reviewed journal covering all subspecialties within ophthalmology. Key topics include: Optometry; Visual science; Pharmacology and drug therapy in eye diseases; Basic Sciences; Primary and Secondary eye care; Patien Safety and Quality of Care Improvements. This journal is indexed on

Submit your manuscript here: http://www.dovepress.com/clinical-ophthalmology-journal

\section{Dovepress}

PubMed Central and CAS, and is the official journal of The Society of Clinical Ophthalmology (SCO). The manuscript management system is completely online and includes a very quick and fair peer-review system, which is all easy to use. Visit http://www.dovepress.com/ testimonials.php to read real quotes from published authors. 